\title{
Urinary Incontinence and Its Association with Physical and Psycho-Cognitive Factors: A Cross-Sectional Study in Older People Living in Nursing Homes
}

\author{
Pau Farrés-Godayol 1,+, Javier Jerez-Roig 1,* , Eduard Minobes-Molina 1, , Meltem Yildrim ${ }^{1}$, Miriam Molas-Tuneu ${ }^{1}$, \\ Anna Escribà-Salvans 1, Sandra Rierola-Folchs ${ }^{1}$, Montse Romero-Mas ${ }^{1}$, Miriam Torres-Moreno ${ }^{1}$, Laura Coll- \\ Planas ${ }^{1,2}$, Joanne Booth ${ }^{3}$ and Maria Giné-Garriga ${ }^{4}$
}

\begin{abstract}
1 Research Group on Methodology, Methods, Models and Outcome of Health and Social Sciences (M3O), Faculty of Health Sciences and Welfare, University of Vic -Central University of Catalonia (UVIC-UCC), 08500, Vic, Spain; pau.farres@uvic.cat (P.F.); eduard.minobes@uvic.cat (E.M.-M.); meltem.yildirim@uvic.cat (M.Y.); miriam.molas@uvic.cat (M.M.-T.); anna.escriba1@uvic.cat (A.E.-S.); sandra.rierola@uvic.cat (S.R.-F.) montse.romero@uvic.cat (M.R.-M.); miriam.torres@uvic.cat (M.T.-M.); laura.coll@uvic.cat (L.C.-P.)

2 Fundació Salut i Envelliment (Foundation on Health and Ageing), Universitat Autònoma de Barcelona, Barcelona, Spain

3 Research Centre for Health, School of Health and Life Sciences, Glasgow Caledonian University, Cowcaddens Road, Glasgow, G4 0BA, UK; jo.booth@gcu.ac.uk

4 Department of Physical Activity and Sport Sciences, Faculty of Psychology, Education and Sport Sciences (FPCEE) Blanquerna, Ramon Llull University, Barcelona, Spain; mariagg@blanquerna.edu

* Correspondence: javier.jerez@uvic.cat; Tel: +34 938816025

+ Equal contribution.
\end{abstract}

\begin{abstract}
Urinary incontinence (UI) is a common geriatric syndrome affecting bladder health and is especially prevalent in nursing homes (NHs). The aim of the study was to determine the prevalence of UI and its associated factors in 5 Spanish NHs. UI (measured with Minimum Data Set 3.0.), sociodemographic and health-related variables were collected. Chi- square (or Fisher's) or Student's ttest (or Mann Whitney U) for bivariate analysis were used, with Prevalence Ratio (PR) as an association measure. The prevalence of UI was $66.1 \%$ (CI:95\%, 53.6-77.2) and was significantly associated with frailty (PR 1.84; 95\%CI 0.96-3.53), faecal incontinence (FI) (PR 1.65; 95\%CI 1.02-2.65), anxiety (PR 1.64; 95\%CI 1.01-2.66), physical performance (PR 1.77; 95\%CI 1.00-3.11) and cognitive state (PR 1.95 ; $95 \%$ CI 1.05-3.60). Statistically significant differences between incontinent-continent groups were found for activities of daily living (ADL) limitations, mobility, quality of life, sedentary behaviour (SB) and handgrip strength. It can be concluded that $2 / 3$ of the residents experienced UI, and its significant associated factors were mainly physical (SB, frailty, physical performance, ADL limitations, mobility, FI and handgrip strength) followed by psycho-cognitive factors (cognition, anxiety and quality of life).
\end{abstract}

Keywords older people; nursing home; incontinence; urinary incontinence; pelvic health; sedentary behaviour; physical health; faecal incontinence; low urinary tract symptoms

\section{Introduction}

The total population of older adults in the European Union (EU), defined as those aged 65 years or older, is projected to increase significantly and will reach 129.8 million by 2050. During this transition, the number of people in the EU aged 75-84 years is projected to expand by $56.1 \%$, while the number aged 65-74 years is expected to increase by $16.6 \%$ [1]. This complex process is caused by low fertility rates, increased life expectancy and, in some cases, migratory patterns. This transition to an aged demographic pyramid in the coming decades will represent a challenge that will have to be managed in every country to provide health and social coverage to many older adults with multimorbidity, due to an increase of chronic conditions associated with age $[2,3]$. 
Lower urinary tract symptoms (LUTS) are a wide variety of symptoms which indicates poor bladder health. These symptoms can be divided into three groups: (a) storage symptoms, experienced during the storage phase of the bladder cycle and include daytime frequency, urinary incontinence (UI) and nocturia; (b) voiding symptoms experienced during the voiding phase including slow stream, hesitancy and straining to start micturition; and (c) post-micturition symptoms experienced immediately after voiding, including incomplete emptying and post-micturition dribbling [4]. LUTS are highly prevalent world-wide but induce low levels of medical consultation [5-8]. LUTS and UI are strongly associated with age, and with an expected increase in mean life expectancy over the next decades, their prevalence is expected to increase together with economic and psychosocial impacts on the health care system $[2,8,9]$.

$\mathrm{UI}$ is the objectively demonstrable involuntary loss of urine which increases the subject's frailty, their physical inactivity, their risk of falls and their immobility, decreases their functional independence and has negative physiological effects due to hygienic problems [4,9-17]. Also, UI greatly impacts on psychological health, severely affects normal social interaction and leisure activities, increases the risk of self-imposed isolation and cognitive impairment and decreases satisfaction and quality of life (QoL)[10,18-22]. There are 5 types of UI: (a) stress UI is the involuntary leakage of urine that occurs with increases in intra-abdominal pressure (e.g., with exertion, effort, sneezing, or coughing); (b) urgency $\mathrm{UI}$ is the involuntary leakage of urine that may be preceded or accompanied by a sense of urinary urgency; (c) mixed UI is the involuntary leakage of urine caused by a combination of stress and urgency UI; (d) overflow UI is the involuntary leakage of urine from an overdistended bladder; and functional UI is the involuntary leakage of urine due to environmental, cognitive or physical barriers to toileting $[23,24]$. In the nursing home $(\mathrm{NH})$ population, the functional UI type stands out, caused by the inability to move to the bathroom independently, whether due to a physical or cognitive problems such as dementia [17].

In the $\mathrm{NH}$ population, $\mathrm{UI}$ is strongly associated with cognitive decline, inactivity, immobility and impairment in activities of daily living performance that could lead to a decrease in physical activity, and an increase of sedentary behavior (SB) $[21,25,26]$. SB is considered a risk factor for cardiovascular disease, metabolic disease, obesity, frailty, disability, psychological disorders, and mortality decline [27-33]. Concerning the relationship between $\mathrm{SB}$ and pelvic health, a previous study found an association between urgency UI and the average duration of SB bouts, and another study found that low levels of physical activity were associated with greater nocturia and nocturnal enuresis, both studies were carried on community dwelling older women [34,35]. In addition, many authors suggest that low levels of physical activity and prolonged patterns of SB could be direct risk factors for UI in older adults [36-40].

To our knowledge there is still no evidence on the association between SB and UI in $\mathrm{NH}$ residents. Consequently, new research is needed to analyze this relationship, with the aim of developing strategies to approach UI to improve resident's health and QoL and reduce the UI burden on social and health services. The main objective of the study is to determine the prevalence of $\mathrm{UI}$ and its associated factors in a cohort of $\mathrm{NH}$ residents. Also, we aimed to verify the prevalence of the different types of LUTS and UI, as well as their impact on residents QoL. 


\section{Materials and Methods}

\subsection{Participants and Procedures}

An observational cross-sectional study was carried out in 5 nursing homes (NHs) of Osona (a central Catalonia County, Spain). This sub study is part of the OsoNaH project [41], registered in Clinical Trials (NCT04297904). The STROBE (STrengthening the Reporting of OBservational studies in Epidemiology) guidelines for cross-sectional studies were followed [42]. The data was extracted from January 2020 and had to stop in March 2020, due to the COVID-19 outbreak. All residents aged 65 years or older who lived permanently for at least the previous 6 months in the NHs were included. Subjects in a coma or palliative care (short-term prognosis), residents who did not have capacity to answer questionnaires and those residents or legal guardians who refused to participate in the study were excluded.

The first contact with the NHs was done by email and phone call to explain the project and to solve any queries. Then, the information sheet and consent forms for the study were sent to them, if they were interested in participating. Every $\mathrm{NH}$ director who accepted the participation of their center in the project signed a formal consent. After that, the list of residents was obtained, and the residents were selected according to the inclusion/exclusion criteria. Then, a simple randomization with the IBM SPSS Statistics software (IBM Corp. Released 2021. IBM SPSS Statistics for Windows, Version 28.0. Armonk, NY: IBM Corp) was done and the selected residents or their legal guardians were informed about the project and those who agreed to participate signed the informed consent. At that time, NH staff were informed about the project and the ones who agreed to participate, also signed the informed consent. The participants were informed that in case of fatigue, they could interrupt or stop the assessment whenever he/she wished. Furthermore, they could withdraw from the study at any time without giving any reasons.

The research team was trained, received standardised operating procedures and the inter-rater reliability was evaluated with the calculation of the Kappa index and the interclass correlation coefficient (ICC) of the data from 20 residents. The CCI scores were greater than 0.75 for all physical tests. The results for these 20 residents were not included in the final total study sample. After the reliability calibration, a pilot study was performed with a separate sample of 36 residents, whose data were included in the final sample.

\subsection{Variables and instruments}

The dependent variable in the study was the presence of UI (yes/no) according to the proxy, by the Section H of Minimum Data Set (MDS) version 3.0 [43]. The presence of UI and other bladder and bowel conditions, urinary catheters and incontinence control programs were also reported by the MDS. Additionally, the international test Consultation on Incontinence Questionnaire Urinary Incontinence-Short Form (ICIQ-SF) [44] and the International Prostate Symptoms Score (IPSS)[45,46] was applied. The ICIQ-SF assesses the quantity, frequency of urine losses, and the impact of the UI on the individual's quality of life (QoL). The type of UI was determined according to the MDS and the ICIQ UI-SF. Information on LUTS and QoL associated with UI were collected using the IPSS. To evaluate the presence of nocturia, the residents and their proxy were also asked about the number of times the resident got up during the night to urinate. Residents with an ostomy and bladder catheterization were categorised as incontinent. Item 1 of the ICIQ-SF was taken as self-reported presence of UI; UI characteristics, LUTS and QoL related to the UI of residents with capacity to answer the questionnaires aimed to compare their self-reported answers with the answers of the NH staff. The ICIQ-SF and IPSS answers were compared with the answers provided by the resident proxy through MDS.

Sedentary behaviour and waking time movement behaviour (WTMB) was assessed by the gold standard ActivPAL3 activity monitor (PAL Technologies Ltd., Glasgow, UK), worn on the anterior medial right thigh that captured the data continuously for 7 consecutive days [47-49]. The following variables were extracted: waking hours, standing duration in hours, \% of waking time standing, walking duration in hours, $\%$ of waking time 
walking, absolute time upright in hours, \% of waking time upright, sit to stand transitions, sit to stand transitions per hour, absolute time sitting in hours, \% of waking time sitting, sitting bouts $<30^{\prime}$, sitting bouts per hour $<30^{\prime}$, total time sitting in $<30^{\prime}$ bouts in hours, $\%$ of waking time in bouts $<30^{\prime}$, sitting bouts $30-60^{\prime}$, sitting bouts per hour $30-60^{\prime}$, total time sitting in 30-60' bouts in hours, \% of waking time in bouts 30-60', sitting bouts $>60^{\prime}$, sitting bouts per hour $>60^{\prime}$, total time sitting in $>60^{\prime}$ bouts in hours, \% of waking time in bouts $>60^{\prime}$ and average duration of SB bouts in minutes.

Activities of daily living limitations were measured using the modified Barthel Index by Shah $e t$ al. $[50,51]$. This scale is meant to be used in the assessment of patient performance or degree of assistance required in self-care, sphincter management, transfers and locomotion. Shah et al. retained the original 10 items but proposed five-point rating scales for each item to improve sensitivity to detecting change. The scale consists of 10 items scored with several points which relate to ADL where the final score is calculated by summing the points awarded to each item. The score categorization is 91-99 slight dependency, 61-90 moderate dependency, 21-60 severe dependency and 0-20 total dependency. The continence items were excluded as already carried out by Jerez Roig et al. and Prado Villanueva et al. [34,52].

Physical performance was examined using the Short Performance Physical Battery (SPPB) [53], the handgrip strength was measured by a Hand dynamometer (JAMAR Plus Digital), with the resident in a sitting position and their elbow at $90^{\circ}$ of flexion; 3 repetitions were done in each hand and the highest value was considered the valid one. The results were assessed and adjusted to gender and body mass index [54]. To assesses frailty the Clinical Frailty Scale (CFS) was chosen, because it is a practical, valid and efficient tool, considered a solid predictor of institutionalization and mortality. It is organized in an ordinal scale of 9 points with clinical descriptions and pictograms where the NH staff has to consider the information about cognition, mobility, functionality and comorbidities according to the history and the physical examination of the resident to choose in which grade of the scale the resident is [55]. The Rivermead Mobility Index assesses functional mobility in gait, balance and transfers in 14 self-reported items and 1 direct observation item that progress in difficulty, with dichotomous answers coded as 0 for a no, indicating an inability to perform the activity or measure and 1 for a yes. The summing of the points for all items indicates the final score, where higher scores indicate better mobility performance [56]. For the sarcopenia risk, The SARC-F questionnaire was used. This is a rapid tool for screening sarcopenia risk, based on 5 components: strength, assistance in walking, rise from chair, climb stairs and falls. The Score range from 0 to 10 , with 0 to 2 points for each component, and the final score of 4 or higher is predictive of sarcopenia $[57,58]$. The QoL using the self-reported questionnaire Spanish Index EuroQoL 5D-5L [59] and the daily consumption of liquids was assessed by a $24 \mathrm{~h}$ liquid consumption diary. The liquid diary had all the approximate volume of drinks in millimetres, the type of drink and if the drink has caffeine or not in a 24-hour period. The diary was completed by the residents, but in the case where the resident did not remember the information, the proxy was asked.

Sociodemographic and health information such as age, gender, level of education, marital status, chronic diseases, smoking and drinking habits and hospitalizations, were obtained from the NH registers and checked with the NH professionals. The total number of medications in daily use were registered, as well as the types of medications, according to the Anatomical Therapeutic Chemical classification system (ATCCS), a drug classification system that classifies the active ingredients of drugs according to the organ or system on which they act and their therapeutic, pharmacological and chemical properties [60]. Also, according to the ATCCS, we categorized the drugs that increase or decrease the micturition, and the residents were assessed according to their categorization of their daily medication with the aim to know if these drugs were related to their UI. Nutritional status was assessed using the Mini Nutritional Assessment (MNA) test, a validated screening tool to help identify elderly patients who are malnourished or at risk of malnutrition. According to the results, individuals can be divided in 3 groups using threshold values of 
$<17$ for 'malnourished', 17-23.5 for 'at risk of malnutrition' and $\geq 24$ for 'normal nutritional status', with a maximum total score of 30 points [61].

Psychosocial factors were considered in all residents: number of monthly visits from friends/family, according to the NH staff, as well as the Yesavage Geriatric Depression Scale (GDS), considered a reliable and valid tool for self-rating of symptoms of depression in older adults 65 years of age or older. Of the 15 answers, 10 indicated the presence of depression when answered positively, while the rest (question numbers 1, 5, 7, 11, 13) indicated depression when answered negatively. Scores of 0-4 are considered normal, depending on age, education, and complaints; 5-8 indicates mild depression; 9-11 indicates moderate depression; and 12-15 indicates severe depression [62]. Cognitive status was assessed using the Pfeiffer Scale which evaluates functions such as orientation, memory, concentration, and arithmetic. The instrument classifies older adults (over 65 years) according to their preserved mental function, mild, moderate, or severe cognitive impairment, considering the educational level of the person being evaluated [63]. For anxiety the Hospital Anxiety and Depression Scale - Anxiety subscale: HADS-A was used. A 7-item anxiety subscale focused mainly on symptoms of generalized anxiety disorder where each item scores on a 4-point Likert scale giving a maximum score of 21 for anxiety. According to the results, the scoring categorization is 0-7 for no anxiety, 8-10 for doubtful cases and $\geq 11$ for definite cases $[10,64]$. Social networks were assessed through the Lubben Social Network Scale - 6 items (LSNS-6). This short version of 6 items scale is a self-report measure of social engagement including family and friends. The LSNS-6 is correlated with mortality, all case hospitalization, health behaviours, depressive symptoms, and overall physical health. The score ranges between 0 and 30, with a higher score indicating more social engagement [65]. For loneliness, the 6-item De Jong-Gierveld Loneliness Scale was used. This questionnaire is a reliable and valid measurement instrument which can be used as a unidimensional overall loneliness measure as well as provide information about the emotional and/or social loneliness situation of respondents. It is an individual's subjective evaluation of his or her social participation or isolation. In this 6-item scale, three answers consider emotional loneliness and three social loneliness. There are negatively (1-3) and positively (4-6) worded items. On the negatively worded items, the neutral and positive answers are scored as " 1 " and on the positively worded items, the neutral and negative answers are scored as " 1 ". Therefore, this gives a possible range of scores from 0 to 6 , which means closer to zero is least lonely and closer to 6 means most lonely [66].

\subsection{Statistical analysis}

The sample size and power analysis was calculated according to the association between the dependent variable (UI yes/no) and the average duration of SB bouts in minutes, since this was the most significant SB variable in a previous study [40]. Since there are no previous studies analysing UI and SB in institutionalized older adults, we used our data for the sample size calculation. Considering a mean of 57.00 minutes (standard deviation-SD: 58.13) as among the incontinent group and 19.94 (SD:12. 64) minutes among the continent group, significance level of 0.05 and power of 0.80 , a minimum sample of 42 individuals was necessary.

Regarding statistical analysis, data obtained during the study were coded at the end of the collection, processed and analysed by the members of the research group. The statistical analysis was carried out with the IBM SPSS Statistics software (IBM Corp. Released 2021. IBM SPSS Statistics for Windows, Version 28.0. Armonk, NY: IBM Corp). First, descriptive analysis was undertaken indicating absolute and relative frequencies for categorical variables and mean and standard deviation (SD) for quantitative variables. Subsequently, bivariate analysis was applied through the Chi square test (or Fisher's test when necessary) and the linear Chi square test in cases of dichotomous or ordinal variables. The normality of data was evaluated with the Kolmogorov-Smirnov test to determine their distribution; for the parametric variables the Student's t-test was used and for the nonparametric variables the Mann Whitney U test was applied. As an association measure, the Prevalence Ratio (PR) was used, with a confidence level of 95\%. 


\section{Results}

The final sample consisted of 68 residents, mostly women $(80.9 \%)$, with a mean age of $83.6 \pm 7.6$ and with an average duration living in the NHs of $29.1 \pm 29.0$ months. From the 68 residents, $66(97.0 \%)$ had descendants, with a mean number of $1.6 \pm 1.5$ descendants, and of the 55 women, $47(69.1 \%)$ had given birth. Figure 1 shows the flow chart of the excluded participants of the study.

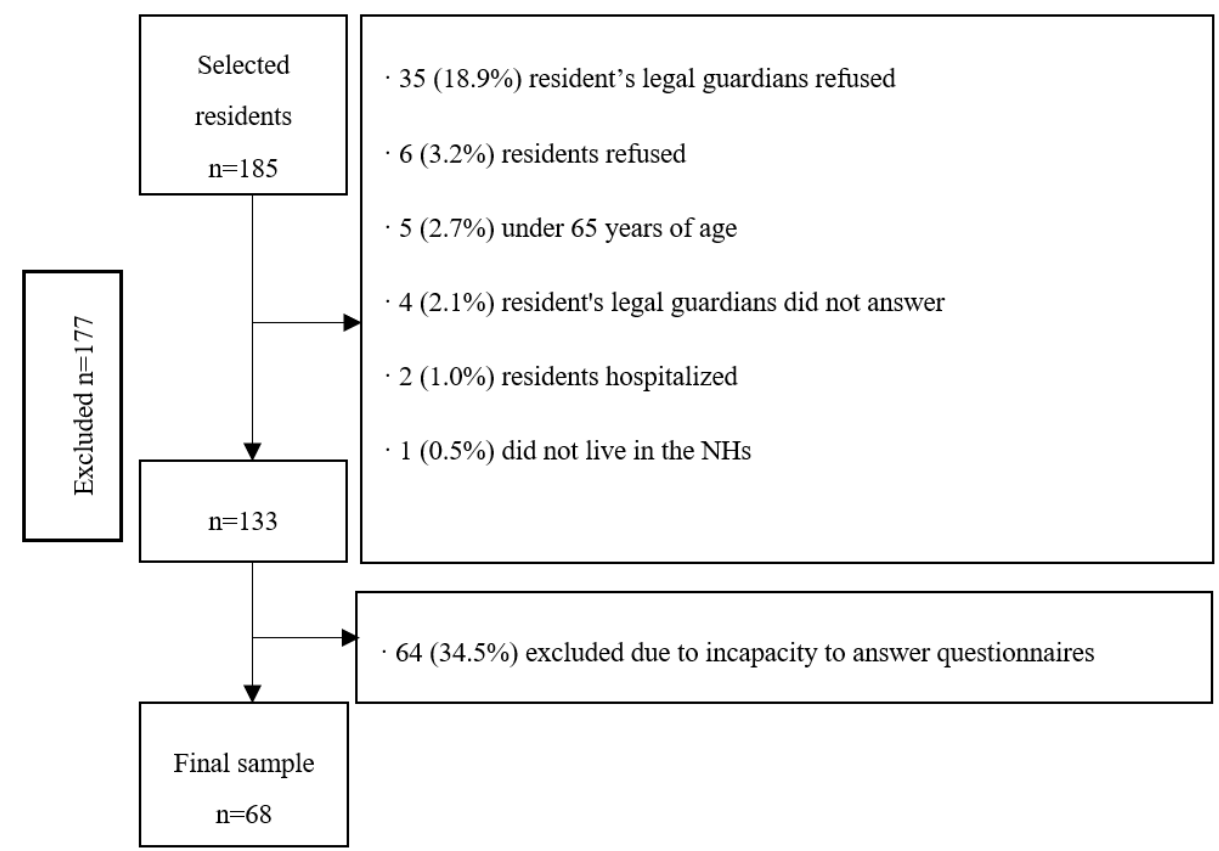

Figure 1. Flow chart of the sampling process of NH residents with capacity to answer questionnaires (Osona, Spain, 2020).

Regarding the presence of diagnosed medical conditions, all 68 (100.0\%) residents were diagnosed with at least one chronic condition, with a mean number of $5.1 \pm 2.3$ diagnosed medical conditions. More specifically: $45(66.2 \%)$ presented arterial hypertension, $30(44.1 \%)$ cardiac disease, $29(42.6 \%)$ dementia, 23 (33.8\%) diabetes, 23 (33.8\%) dyslipidaemia, 22 (32.4\%) kidney failure, 20 (29.4\%) depression, $14(20.6 \%)$ lung disease, 12 (17.6\%) mental disease, 12 (17.6\%) Parkinson's disease, 12 (17.6\%) stroke, 11 (16.2\%) circulatory disease, $11(16.2 \%)$ digestive disease, $11(16.2 \%)$ hypothyroidism, $10(14.7 \%)$ cancer, $10(14.7 \%)$ diagnosed osteoporosis, $7(10.3 \%)$ anaemia, 7 (10.3\%) arthrosis, $6(8.8 \%)$ vertigo, $5(7.4 \%)$ anxiety, 5 (7.4\%) chronic pain, 5 (7.4\%) visual deficit, 3 (4.4\%) epilepsy, $3(3.4 \%)$ hiatal hernia, 3 (4.4\%) low blood pressure, 2 (2.9\%) Hyperparathyroidism, $1(1.5 \%)$ hyperthyroidism and $1(1.5 \%)$ sleep disorders. Concerning pelvic health, $3(4.4 \%)$ individuals had prostatic hyperplasia and $2(2.9 \%)$ diagnosed vaginal prolapse.

It was found that $48(70.5 \%)$ residents had cognitive decline, $62(91.1 \%)$ presented functional dependency, $62(91.1 \%)$ decreased functional capacity and frailty, 50 (73.5\%) had risk of sarcopenia, $3(48.5 \%)$ had risk of malnutrition, $58(85.2 \%)$ residents presented depressive symptomatology and $46(67.6 \%)$ presented loneliness. All residents were using medication, with an average of $8.3 \pm 10.4$ medications per day, $52(76.5 \%)$ residents were taking 5 medications or more and $42(61.8 \%)$ were at risk of anticholinergic adverse effects. It was identified that $30(44.1 \%)$ residents had fallen at least one time in the last year, 17 (25.0\%) had episodes of delirium, $9(13.2 \%)$ had lost weight in the last 12 months, $8(11.8 \%)$ had skin lesions and $2(2.9 \%)$ had leg ulcers. Also, in the last 12 months, $5(7.4 \%)$ were hospitalized and, $4(5.9 \%)$ had a bone fracture. Table 1 shows socio-demographic and health-related information. 
Table 1. Socio-demographic and health-related information of five NHs ( $n=68)$ from Osona, Spain (2020).

\begin{tabular}{|c|c|c|}
\hline & $\mathbf{n}$ & Frequency (\%) \\
\hline \multicolumn{3}{|l|}{ Education level } \\
\hline Illiterate & 21 & 30.9 \\
\hline Primary school & 29 & 43.3 \\
\hline High school & 5 & 7.4 \\
\hline College education & 3 & 4.4 \\
\hline Unknown & 10 & 14.7 \\
\hline \multicolumn{3}{|l|}{ Marital status } \\
\hline Single & 11 & 16.2 \\
\hline Married/dating & 7 & 10.3 \\
\hline Divorced & 2 & 2.9 \\
\hline Widow(er) & 46 & 67.6 \\
\hline Unknown & 2 & 2.9 \\
\hline \multicolumn{3}{|c|}{ Medication (ATC Classification) a } \\
\hline Group A & 46 & 67.6 \\
\hline Group B & 35 & 51.5 \\
\hline Group C & 41 & 60.3 \\
\hline Group D & 2 & 2.9 \\
\hline Group G & 5 & 7.4 \\
\hline Group H & 13 & 19.1 \\
\hline Group J & 2 & 2.9 \\
\hline Group L & 1 & 1.5 \\
\hline Group M & 5 & 7.4 \\
\hline Group N & 66 & 97.1 \\
\hline Group R & 13 & 19.1 \\
\hline Group S & 4 & 5.9 \\
\hline Group V & 1 & 1.5 \\
\hline \multicolumn{3}{|l|}{ Body Mass Index (BMI) } \\
\hline Under weight & 11 & 16.2 \\
\hline Normal/Overweight & 28 & 41.2 \\
\hline Obese & 16 & 23.5 \\
\hline Unknown & 13 & 19.1 \\
\hline \multicolumn{3}{|c|}{ Overall physical condition (Clinical Frailty Scale) } \\
\hline Very fit & 1 & 1.5 \\
\hline Well & 13 & 19.1 \\
\hline Managing Well & 4 & 5.9 \\
\hline Vulnerable & 2 & 2.9 \\
\hline Mildy Frail & 16 & 23.5 \\
\hline Moderately Frail & 25 & 36.8 \\
\hline Severely Frail & 1 & 1.5 \\
\hline Very Severely Frail & 0 & 0.0 \\
\hline Terminally ill & 0 & 0.0 \\
\hline \multicolumn{3}{|c|}{ Physical performance (SPPB) } \\
\hline Robustness & 3 & 4.4 \\
\hline Prefrailty & 9 & 13.2 \\
\hline Frailty & 19 & 27.9 \\
\hline Disability & 34 & 50.0 \\
\hline \multicolumn{3}{|l|}{ ADL limitations (Barthel) } \\
\hline Independent & 7 & 10.3 \\
\hline Slight dependency & 10 & 14.7 \\
\hline
\end{tabular}


Moderate dependency

Severe dependency

Cognitive state (Pfeiffer)

Intact

Slight cognitive impairment

Moderate cognitive impairment

Severe cognitive impairment

Social Isolation (Lubben scale)

No risk

Low risk

High risk

DNK/DNA

Anxiety (Hospital Anxiety and Depression Scale)

Normal

Doubtful case

Definite case

DNK/DNA

Depressive symptoms (Geriatric Depression Scale)

No

Positive

Suspected

Loneliness (The De Jong Gierveld Loneliness Scale)

No

Positive

DNK/DNA

Nutritional state (Mini Nutritional Assessment)

Normal nutritional status

At risk of malnutrition

Malnourshed

DNK/DNA
11

1

4

58

6

19

46

3
1.5

27.9

67.6

4.4

41.2

47.1

10.3

Own elaboration; Note : DNK/DNA = did not know/did not answer; a Drugs : N (Nervous System), A (Alimentary tract and metabolism), C (Cardiovascular system), B (Blood and blood forming organs), R (Respiratory System), H (Systemic hormonal preparations, excl. Sex hormones and insulins), G (Genito urinary System/sex hormones), M (Musculo-skeletal system), S (Ophthalmologicals), J (Antiinfectives), D (Dermatologicals), L (Antineoplastic agents) and V (Immunomodulating agents).

Concerning SB and the waking time movement behaviour (WTMB) of the residents, their average upright time was $2.2 \pm 1.8$ hours, sitting time was $8.8 \pm 1.6$ hours, and the average duration of SB bouts was $44.6 \pm 50.9$ minutes. Also, $43(63.2 \%)$ residents follow at least once per week a physical exercise program led by $\mathrm{NH}$ staff. Most of the residents who participated in the physical exercise programs had UI. Table 2 shows more information about SB and WTMB. 
Table 2. SB and WTMB information of five NHs from Osona, Spain (2020).

\begin{tabular}{|c|c|c|}
\hline & Mean & Standard deviation $( \pm)$ \\
\hline Waking hours & 11.1 & 1.4 \\
\hline Standing duration $(\mathrm{h})$ & 1.8 & 1.5 \\
\hline$\%$ of waking time standing & 15.9 & 13.2 \\
\hline Walking duration (h) & 0.4 & 0.4 \\
\hline$\%$ of waking time walking & 3.7 & 4.4 \\
\hline$\%$ of waking time upright & 19.7 & 15.7 \\
\hline Sit to stand transitions & 26.0 & 19.0 \\
\hline Sit to stand transitions per hour & 2.0 & 2.0 \\
\hline$\%$ of waking time sitting & 80.2 & 15.8 \\
\hline Sitting bouts $<30$ & 22.0 & 19.0 \\
\hline Sitting bouts per hour $<30$ & 2.0 & 2.0 \\
\hline Total time sitting in $<30$ ' bouts $(\mathrm{h})$ & 2.0 & 1.4 \\
\hline$\%$ of waking time in bouts $<30$ & 17.5 & 12.5 \\
\hline Sitting bouts $30-60$ & 3.0 & 2.0 \\
\hline Sitting bouts per hour $30-60$ & 0.2 & 0.1 \\
\hline Total time sitting in $30-60$ ' bouts $(\mathrm{h})$ & 1.8 & 1.2 \\
\hline$\%$ of waking time in bouts $30-60$ & 16.2 & 10.4 \\
\hline Sitting bouts $>60$ & 2.0 & 0.9 \\
\hline Sitting bouts per hour $>60$ & 0.2 & 0.1 \\
\hline Total time sitting in $>60^{\prime}$ bouts $(\mathrm{h})$ & 4.9 & 3.1 \\
\hline$\%$ of waking time in bouts $>60$ & 46.4 & 32.5 \\
\hline
\end{tabular}

Own elaboration; Note: hours $=(\mathrm{h}) ;$ minutes $=(\mathrm{min})$.

Regarding pelvic health, $2(2.9 \%)$ residents had a permanent catheter, $4(5.9 \%)$ residents had experienced urinary tract infection in the previous 30 days, $60(88.2 \%)$ residents took medication that decreased their micturition, $54(79.4 \%)$ residents took medications that produce an increase in micturition and $21(30.9 \%)$ took laxatives. The total average liquid consumption was $1864.1 \pm 804.7$ millilitres $(\mathrm{ml}): 12.19 \pm 56.61 \mathrm{ml}$ of cold drinks with caffeine, $228.13 \pm 316.83 \mathrm{ml}$ of hot drinks with caffeine, $1396.48 \pm 633.73 \mathrm{ml}$ of non-caffeine cold drinks, $121.70 \pm 206.93 \mathrm{ml}$ of non-caffeine hot drinks and $2.34 \pm 13.88 \mathrm{ml}$ of alcohol. Nocturia (1+ waking at night to urinate) was reported in $21(30.8 \%)$ residents by the proxy and $31(45.5 \%)$ residents self-reported nocturia with the IPSS questionnaire.

According to the MDS, 44 residents presented with UI, i.e., prevalence of $66.1 \%$ (CI: 95\%, 53.6-77.2). Among these, 33 (48.5\%) had UI for more than a year, 22 (32.4\%) had urinary leakage day and night and $31(45.6 \%)$ had large amounts of urinary leakage. From the $26(38.2 \%)$ that were following a toileting program only $8.8 \%$ totally improved their continence with the program. Besides, 12 residents had FI, i.e., prevalence of $17.6 \%$ (CI: 95\%, 10.3-28.3). From these 12 residents, 11 (16.1\%) presented double incontinence. 23 (33.8\%) followed a toileting program, $12(17.6 \%)$ had constipation and $5(7.4 \%)$ diarrhoea. The average of faecal evacuations was $3.0 \pm 3.5$. In the total sample, the average number of diapers per resident was $2.2 \pm 2.0$ per day, and within the incontinent group, $3.2 \pm 1.8$. Table 3 shows UI and FI-related variables, according to the MDS. 
Table 3. UI and FI characteristics, according to MDS among 68 residents living in 5 NHs from Osona, Spain (2020).

\begin{tabular}{lcc}
\hline & Sample (n) & Frequency (\%) \\
\hline Urinary toileting programme response & 8 & 30.7 \\
No improvement & 11 & 42.3 \\
Decreased wetness & 6 & 23.0 \\
Completely dry (continent) & 1 & 3.8 \\
$\quad$ Unable to determine (or trial in progress) & & 35.5 \\
UI & 24 & 39.7 \\
Always continent & 27 & 14.7 \\
Occasionally incontinent & 10 & 7.4 \\
Frequently incontinent & 5 & 2.9 \\
Always incontinent & 2 & 25.0 \\
Not rated & & 1.5 \\
Predominant type of UI & 17 & 23.5 \\
Urgency UI & 1 & 22.1 \\
Stress UI & 16 & 2.9 \\
Cognitive decline UI & 15 & \\
Functional UI & 2 & 83.8 \\
Indeterminate & & 8.8 \\
FI & 57 & 4.4 \\
Always continent & 6 & 2.9 \\
Occasionally incontinent & 3 & \\
Frequently incontinent & 2 & \\
Always incontinent & & \\
\hline
\end{tabular}

Own elaboration.

According to the ICIQ-SF, 35 (51.4\%) residents self-reported UI at least once a week. Among these, 17 (25.0\%) before reaching a toilet, 19 (27.9\%) when he/she coughs/sneezes, 23 (33.8\%) whilst asleep, 13 (19.1\%) during physical activity/exercise, 10 (14.7\%) after urination while already is dressed, $7(10.2 \%)$ for no obvious reason and $6(8.8 \%)$ all the time. Regarding the frequency of urinary leakage, 11 (16.1\%) subjects had leakages at least one time per week and 24 (35.2\%) had daily losses. The urine leakage was low in $13(19.1 \%)$ subjects, moderate in $11(16.1 \%)$ and large amounts in $12(17.6 \%)$ residents. According to the MDS questionnaire, $7(10.2 \%)$ incontinent residents reported no urine leakage or refused to answer. The impact of UI on, QoL was low (score 0-3) in $22(56.4 \%)$ subjects, moderate (4-6) in $8(20.5 \%)$ and high (7-10) in $9(23.0 \%)$ residents.

In the information gathered from the IPSS, bladder symptoms reported at least once in the last 30 days were: urgency 37 (54.4\%), increased frequency 36 (52.9\%), incomplete emptying $20(29.4 \%)$, intermittency 18 (26.4\%), weak stream $16(23.5 \%)$ and straining 15 $(22.0 \%)$. For the QoL associated with prostatic symptoms 10 (14.7\%) were delighted, 7 (10.3\%) pleased, 16 (23.5\%) mostly satisfied, 10 (14.7\%) mixed, 12 (17.6\%) not satisfied, 6 $(8.8 \%)$ unhappy and 4 (5.9\%) terrible. Table 4 shows the classification of bladder symptoms and UI according to the ICIQ-SF and IPSS. 
Table 4. Self-reported information on UI and bladder symptoms according to the IPSS and ICIQ-SF among 68 residents living in 5 NHs from Osona, Spain (2020)

\begin{tabular}{lcc}
\hline $\begin{array}{l}\text { Tf-reported information on UI and bladder symptoms according to the IPSS and ICIQ-SF } \\
\text { among } 68 \text { residents living in } \mathbf{5} \text { NHs from Osona, Spain (2020). }\end{array}$ \\
\hline \multicolumn{2}{c}{ Sample (n) } & Frequency (\%) \\
\hline Final IPSS classification & 36 & 52.9 \\
Mild (0-7) & 21 & 30.9 \\
Moderate (8-19) & 7 & 10.3 \\
Severe (20-35) & 4 & 5.9 \\
Unknown & & \\
Continence status by ICIQ-SF & 26 & 38.2 \\
Continent (0) & 18 & 26.5 \\
Slight (1-5) & 10 & 14.7 \\
Moderate (6-12) & 8 & 11.8 \\
Severe (13-18) & 3 & 4.4 \\
Very severe (19-21) & 3 & 4.4 \\
Unknown
\end{tabular}

Own elaboration.

Table 5 shows the results of the bivariate analysis and Table 6 and 7 shows the group comparisons of the quantitative variables grouped by the dependent variable (UI) with $p$ value equal or under 0.20 . The variables that were significantly associated with UI were anxiety, physical performance, cognitive status, frailty and FI.

Table 5. Association between UI (according to the MDS) and categorical independent variables with $p$ value under 0.20 among 68 residents living in 5 NHs from Osona, Spain (2020).

\begin{tabular}{|c|c|c|c|c|c|c|}
\hline \multicolumn{7}{|c|}{ UI } \\
\hline & \multicolumn{2}{|c|}{ Yes } & \multicolumn{2}{|c|}{ No } & \multirow[b]{2}{*}{$p$} & \multirow[b]{2}{*}{$\begin{array}{c}\text { PR } \\
(\mathrm{CI}: 95 \%)\end{array}$} \\
\hline & $\begin{array}{l}\text { Sample } \\
\text { (n) }\end{array}$ & $\begin{array}{c}\text { Frequency } \\
(\%)\end{array}$ & $\begin{array}{l}\text { Sample } \\
\text { (n) }\end{array}$ & $\begin{array}{c}\text { Frequency } \\
(\%)\end{array}$ & & \\
\hline \multicolumn{7}{|l|}{ Hypertension } \\
\hline No & 12 & 52.2 & 11 & 47.8 & \multirow[t]{2}{*}{0.081} & 1.00 \\
\hline Yes & 33 & 73.3 & 12 & 26.7 & & $1.55(0.82-2.95)$ \\
\hline \multicolumn{7}{|l|}{ Dementia } \\
\hline No & 23 & 59.0 & 16 & 41.0 & \multirow[t]{2}{*}{0.145} & 1.00 \\
\hline Yes & 22 & 75.9 & 7 & 24.1 & & $1.77(1.03-3.02)$ \\
\hline \multicolumn{7}{|l|}{ Kidney failure } \\
\hline No & 33 & 71.7 & 13 & 28.3 & \multirow[t]{2}{*}{0.161} & 1.00 \\
\hline Yes & 12 & 54.5 & 10 & 45.5 & & $0.70(0.37-1.32)$ \\
\hline \multicolumn{7}{|l|}{ Delirium } \\
\hline No & 31 & 60.8 & 20 & 39.2 & \multirow[t]{2}{*}{0.104} & 1.00 \\
\hline Yes & 14 & 82.4 & 3 & 17.6 & & $1.62(1.01-2.60)$ \\
\hline \multicolumn{7}{|l|}{ Anticholinergic risk } \\
\hline No & 14 & 56.0 & 11 & 44.0 & \multirow[t]{2}{*}{0.133} & 1.00 \\
\hline Yes & 31 & 73.8 & 11 & 26.2 & & $1.33(0.75-2.34)$ \\
\hline \multicolumn{7}{|l|}{ Anxiety (HADS-A) } \\
\hline No & 29 & 59.2 & 20 & 40.8 & \multirow[t]{2}{*}{$\begin{array}{c}0.014^{\mathrm{b}}, \\
*\end{array}$} & 1.00 \\
\hline Yes & 14 & 93.3 & 1 & 6.7 & & $1.64(1.01-2.66)$ \\
\hline \multicolumn{7}{|l|}{ Exercise program participation } \\
\hline Yes & 31 & 72.1 & 12 & 27.9 & \multirow[t]{2}{*}{0.176} & 1.00 \\
\hline No & 14 & 56.0 & 11 & 44.0 & & $0.70(0.38-1.29)$ \\
\hline \multicolumn{7}{|l|}{ SPPB } \\
\hline Robustness - Prefrailty - Frail & 16 & 51.6 & 15 & 48.4 & \multirow[t]{2}{*}{$0.018^{*}$} & 1.00 \\
\hline Disability & 27 & 79.4 & 7 & 20.6 & & $1.77(1.00-3.11)$ \\
\hline \multicolumn{7}{|l|}{ Mini Nutritional Assessment (MNA) } \\
\hline Normal & 16 & 57.1 & 12 & 42.9 & \multirow[t]{2}{*}{0.123} & 1.00 \\
\hline At risk - Malnourished & 25 & 75.8 & 8 & 24.2 & & $1.94(1.00-3.74)$ \\
\hline
\end{tabular}




\begin{tabular}{|c|c|c|c|c|c|c|}
\hline \multicolumn{7}{|l|}{ Pfeiffer Questionnaire } \\
\hline Normal - Slight & 17 & 53.1 & 15 & 46.9 & \multirow[t]{2}{*}{$0.032 *$} & 1.00 \\
\hline Moderate - Severe & 28 & 77.8 & 8 & 22.2 & & $1.95(1.05-3.60)$ \\
\hline \multicolumn{7}{|l|}{ Clinical Frailty Scale (CFS) } \\
\hline $\begin{array}{l}\text { Very fit - Well - Managing Well - Vulnerable - Mildly } \\
\text { Frail }\end{array}$ & 20 & 55.6 & 16 & 44.4 & \multirow[t]{2}{*}{$0.003 *$} & 1.00 \\
\hline $\begin{array}{l}\text { Moderately Frail - Severely Frail - Very Severely Frail } \\
\text { - Terminally ill }\end{array}$ & 25 & 78.1 & 7 & 21.9 & & $1.84(0.96-3.53)$ \\
\hline \multicolumn{7}{|l|}{ Faecal Incontinence } \\
\hline No & 34 & 60.7 & 22 & 39.3 & \multirow[t]{2}{*}{$0.006^{*}$} & 1.00 \\
\hline Yes & 11 & 91.7 & 1 & 8.3 & & $1.65(1.02-2.65)$ \\
\hline
\end{tabular}

Own elaboration. Note: * Statistically significant; ${ }^{b}$ Fisher's Exact Test.

Regarding the comparison between the continent and the incontinent groups, the differences between groups were statistically significant in the variables of QoL, ADL limitations, mobility, handgrip strength and all the SB and WTMB variables (see Table 6 and Table 7).

Table 6. Association between UI and parametric variables with the independent samples T-test among 68 residents living in $5 \mathrm{NHs}$ from Osona, Spain (2020).

\begin{tabular}{|c|c|c|c|c|c|c|c|}
\hline \multicolumn{8}{|c|}{ UI } \\
\hline & \multicolumn{2}{|c|}{ Yes } & \multicolumn{2}{|c|}{ No } & \multirow[b]{2}{*}{ Mean difference } & \multirow[b]{2}{*}{$t$} & \multirow[b]{2}{*}{$p$} \\
\hline & Mean & SD & Mean & SD & & & \\
\hline Waking duration (h) & 10.76 & 1.55 & 11.90 & 0.71 & 1.13 & 3.58 & $<0.001^{*}$ \\
\hline Absolute time sitting in events $<30 \mathrm{~min}$ & 1.72 & 1.55 & 2.57 & 1.14 & 0.85 & 2.01 & 0.050 \\
\hline$\%$ time sitting in events $<30 \mathrm{~min}$ & 14.09 & 10.93 & 20.60 & 7.89 & 7.35 & 2.03 & $0.048 *$ \\
\hline$\%$ time sitting in events between $30-60 \mathrm{~min}$ & 14.09 & 10.93 & 20.60 & 7.89 & 6.50 & 2.42 & $0.019 *$ \\
\hline Absolute time spent in events $>60 \mathrm{~min}$ & 5.67 & 3.34 & 3.62 & 2.21 & -2.04 & -2.60 & $0.012 *$ \\
\hline Dominant hand Handgrip & 12.57 & 6.03 & 18.35 & 8.13 & 5.77 & 2.98 & $0.014 *$ \\
\hline
\end{tabular}

Own elaboration. Note: $\mathrm{n}=$ sample; $\%$ = frequency; $\mathrm{SD}=$ standard deviation; $p=\mathrm{p}$ value; $\mathrm{h}=$ hours; $\min =$ minutes; ${ }^{*}$ Statistically significant;.

Table 7. Association between UI and non-parametric variables through the Mann-Whitney U test among 68 residents living in 5 NHs from Osona, Spain (2020).

\begin{tabular}{|c|c|c|c|c|c|c|}
\hline \multicolumn{7}{|c|}{ UI } \\
\hline & \multicolumn{2}{|c|}{ Yes } & \multicolumn{2}{|c|}{ No } & \multirow[b]{2}{*}{$\boldsymbol{U}$} & \multirow[b]{2}{*}{$p$} \\
\hline & Mean Rank & Sum of Ranks & Mean Rank & Sum of Ranks & & \\
\hline Spanish Index EuroQoL 5D-5L & 29.55 & 1300.00 & 42.52 & 978.00 & 310.00 & $0.010^{*}$ \\
\hline Barthel & 28.21 & 1269.50 & 46.80 & 1076.50 & 234.50 & $<0.001 *$ \\
\hline Rivermead Mobility Index & 27.64 & 1244.00 & 47.91 & 1102.00 & 209.00 & $<0.001 *$ \\
\hline$\%$ of waking time standing & 22.00 & 748.00 & 34.00 & 578.00 & 153.00 & $0.007 *$ \\
\hline$\%$ of waking time walking & 22.29 & 758.00 & 33.41 & 568.00 & 163.00 & $0.012 *$ \\
\hline Absolute time spent walking (h) & 22.29 & 758.00 & 33.41 & 568.00 & 163.00 & $0.012 *$ \\
\hline Absolute time spent upright (h) & 22.18 & 754.00 & 33.65 & 572.00 & 159.00 & $0.009 *$ \\
\hline$\%$ of waking time upright $(\mathrm{h})$ & 22.06 & 750.00 & 33.88 & 576.00 & 155.00 & $0.007 *$ \\
\hline Sit to stand transitions & 22.76 & 774.00 & 32.47 & 552.00 & 179.00 & $0.028 *$ \\
\hline Sit to stand transitions per hour awake & 3.09 & 785.00 & 31.82 & 514.00 & 190.00 & $0.048 *$ \\
\hline$\%$ of waking time sitting & 29.94 & 1018.00 & 18.12 & 308.00 & 155.00 & $0.007 *$ \\
\hline Number of $<30 \mathrm{~min}$ bouts & 23.04 & 783.00 & 31.91 & 542.00 & 188.50 & $0.045^{*}$ \\
\hline Number of $<30$ min bouts per hour & 23.00 & 782.00 & 32.00 & 544.00 & 187.00 & $0.042 *$ \\
\hline Absolute time sitting in events between $30-60 \mathrm{~min}$ & 22.09 & 751.00 & 33.82 & 575.00 & 156.00 & $0.008^{*}$ \\
\hline$\%$ of time sitting in events $>60 \mathrm{~min}$ & 29.00 & 986.00 & 20.00 & 340.00 & 187.00 & $0.042 *$ \\
\hline $\begin{array}{l}\text { Average duration of sedentary behaviour bouts in } \\
\text { min }\end{array}$ & 28.91 & 983.00 & 20.18 & 343.00 & 190.00 & $0.048 *$ \\
\hline
\end{tabular}

Own elaboration. Note: $\mathrm{n}=$ sample; $\%$ = frequency; $\mathrm{U}=$ Mann Whitney $\mathrm{U} ; \mathrm{p}=\mathrm{p}$ value; $\mathrm{h}=$ hours; $\min =$ minutes; ${ }^{*}$ Statistically significant;. 


\section{Discussion}

This study aimed to verify the prevalence of UI and its associated factors in a sample of $\mathrm{NH}$ residents from Osona (Spain), as well as report information on other pelvic health issues such as FI and bladder symptoms. The findings indicate that the prevalence of UI was high, approximately $66 \%$. Physical health issues (physical performance, frailty, FI, ADL limitations, mobility, SB and dominant hand handgrip strength and psycho-cognitive issues (anxiety, cognitive state and quality of life) were significantly associated with UI.

When comparing other studies in NH residents with capacity to answer questionnaires, the prevalence of UI is higher than the one found by Jerez-Roig et al. (2015) among Brazilian NH residents, with a prevalence of $42 \%$ [67]. but slightly lower than the Jachan et al. (2019) study, with a prevalence of 70\% in German NH residents [13]. In all these studies, the MDS was used to assess the UI, except Jachan et al. who used the ICIQ-SF. Regarding other information on pelvic health given by the MDS, we found a prevalence of FI of $35 \%$ and $30 \%$ for the double incontinence (faecal and urinary). An existing systematic review found a median of prevalence for FI of $42.8 \%$ and $65 \%$ for double incontinence [68]. Our prevalence results are lower for the double incontinence, however regarding FI, the results are between the ranges they found.

Regarding LUTS, the most prevalent ones were storage symptoms, i.e., urgency, increased frequency and nocturia, followed by voiding symptoms, intermittency, straining and weak stream; post micturition symptoms [incomplete emptying], more common in men, were less frequent. In line with our results, a study conducted in community-dwelling older adults from Korea also found that storage symptoms were more prevalent than voiding symptoms and much more than post micturition symptoms [8]. For nocturia, residents tended to self-report its presence more often with the IPSS than did the NH staff using the MDS. These findings might be partially explained due to NH staff not recording residents' voiding patterns, and residents not having a voiding diary routine. Since every resident's room has its own private bathroom, particularly for the residents with preserved autonomy, the NH staff might not be aware of who is getting up at night to urinate. This is a possible hypothesis which could explains why the residents reported a higher nocturia than the NH staff $[69,70]$.

The prevalence of the different types of UI differs between the self-reported IPSS and the NH staff report. According to the self-reported ICIQ-SF, the most prevalent type of UI was nocturnal, followed by stress, urgency, dribbling after micturition, indeterminate and finally continuous UI. Nevertheless, NH staff reported that the most prevalent type of UI was urgency, followed by UI due to cognitive decline, functional, indeterminate UI, stress and finally effort UI. These differences between self-reported and NH staff answers, could partially be explained by the difficulties of the $\mathrm{NH}$ staff in classifying the UI types due to a lack of knowledge on pelvic health disorders, also may be due to the culture of secrecy and profound sense of shame felt by those that suffer from UI, which makes it very difficult to talk about it and look for help through the NH staff or health professionals because they may feel uncomfortable, embarrassed or ashamed, as previous studies have reported [71-75]. This sense of shame and secrecy from the subjects with UI is well reported by previous evidence that profoundly affects their QoL in the domains of dignity, autonomy and mood $[19,73,76]$.

Incontinent residents had worse self-reported QoL than continent residents. UI can occur rapidly and in large volumes, which severely affects normal social participation among affected people [18]. It also increases the risk of isolation and decreases satisfaction with life. As a result, a decrease in QoL and functional independence of the resident can be observed, which may lead to greater frailty. There are different risk factors -which could cause this decline in QoL, including gender, age, dementia and mobility and the embarrassment of leaking urine and being wet can make residents feel a loss of personal dignity [76]. DuBeau et al. (2007), also showed that frail, functionally and cognitively disabled residents with UI experienced a decrease in QoL [77]. 
Our study results also show that approximately $3 / 4$ of the sample who self-reported UI answered that UI had a low-moderate impact on their QoL, a lower proportion compared to previous studies. A review in Brazilian NH residents found that the impact of UI in QoL was higher than in our study, with approximately $57 \%$ reporting low-moderate impact [78]. Similarly, Jachan et al. (2019) found that $51 \%$ of incontinent German NH residents had a low-moderate impact on their QoL, according to ICIQ-SF [13].

Regarding LUTS and their impact on QoL, our results showed that most incontinent residents have good QoL. To our knowledge, there is no evidence of the impact of LUTS on QoL in NH residents. The evidence in community-dwelling older adults shows that prostatic symptoms and their severity increases with age, and also their higher frequency of poor QoL [79-81]. However, our results did not coincide with these previous statements, although they were in line with the results of the studies done by Adegun et al. (2016) and Ojewola et al. (2016) who found that even mild symptomatology could be associated with poor QoL whereas some severe symptomatology could be associated with good QoL [80,81].

Regarding SB and WTMB, the incontinent group showed statistically significant differences in lower periods of time spent standing, walking and in upright position, lower duration of time spent sitting in bouts of $<30 \mathrm{~min}$ and bouts between 30 and $60 \mathrm{~min}$, as well as higher time spent sitting in bouts of $>60 \mathrm{~min}$ than the continent group. Researchers still do not identify a threshold for how many consecutive minutes of sitting are needed before health risks are increased, but previous evidence suggests that sitting for as little as 20 consecutive minutes affects cardiometabolic health [82]. In line with the evidence of our study results, previous studies found statistical significance between UI and almost $20 \%$ longer duration of sedentary bouts in community-dwelling older women $[40,83]$. These findings could reinforce the hypothesis that the main risk factors of SB are the duration of the sitting bouts more than the total time spent sitting. Finally, evidence suggests that $\mathrm{SB}$ is a risk factor for $\mathrm{UI}$ in older adults. Hence, future interventions of increasing physical activity and breaking large SB bouts could be beneficial in preventing these symptoms $[15,34,84]$.

Regarding factors associated with UI, our results show that incontinent residents had greater decline in their physical health and in their psycho-cognitive health than the continent individuals. On psycho-cognitive health, UI as a geriatric syndrome, has been strongly associated with cognitive decline and higher anxiety and depression levels in previous studies $[18,22]$. Regarding physical health, researchers over the years have found a strong association between UI and ADL limitations, frailty, physical performance and overall physical condition loss $[12,14,21,26,67,85,86]$. But there is no research done in $\mathrm{NH}$ populations to explain the results between low handgrip strength in incontinent residents, however Bag Soytas et al. (2021) found a positive correlation between low handgrip strength and quantitatively measured weak pelvic floor muscle strength in adult women, a characteristic related to multiple causes in the pathophysiology of UI in women $[87,88]$. This could be one of multiples possible explanations, however, more research is needed to explain it in different populations and in both genders. In addition, fluid intake, mobility, and diuretic treatment may also influence diuresis and, therefore $\mathrm{UI}_{\mathbf{L}} \mathrm{In}$ our study sample, neither medication nor total fluid intake were found to be significantly associated with UI. It could be interesting for further research to examine effects of these variables on UI in a longitudinal study [19].

The main limitation of this study was the small sample size ${ }_{L}$ due to the COVID-19 outbreak that interrupted the data collection in NHs in March 2020 and reduced the number of participants initially estimated for the project. Consequently, a multivariate analysis of the significant variables could not be performed. In addition, since individuals without capacity to answer questionnaires were excluded from our study sample, the results cannot be generalized to residents with cognitive decline. Despite this, our sample size has sufficient power to analyze the association between UI and the average time of sedentary bouts, since the differences between groups were high. Studies with a larger sample size including confounders in multivariate analysis are required to specifically 
analyze the role of SB in pelvic health. Also, the cross-sectional design of this study prevents establishing any cause-effect relationships between the variables; longitudinal designs are necessary to analyze these pathways. On the other hand, this study is the first that investigated the association between UI and SB in NH residents (considering both sexes), using the gold standard device ActivPAL to accurately measure SB. To our knowledge, this is also the first study describing LUTS and analyzing the association between UI and handgrip strength in institutionalized older adults. These results may be useful for the creation of new strategies to prevent UI and the SB effects on the NH population.

\section{Conclusions}

Our study found a high prevalence of UI demonstrating that it affects approximately 2 out of $3 \mathrm{NHs}$ residents in Osona- Incontinent residents had a greater decline in their physical health and in their psycho-cognitive health than the continent individuals. Incontinent residents had worse self-reported QoL than continent residents, but the specific impact of UI and LUTS on QoL was diverse. The results of this study found an association between UI and the average duration of sedentary bouts instead of the total time spent sitting. These findings could suggest that the main SB risk factor for UI relies on the duration of the individual SB bouts rather than the total time sitting accumulated during the day, but further investigation is needed to confirm this hypothesis.

Author Contributions: Conceptualization, P.F.; J.J; A.E.; S.R.; M.M. and E.M.; methodology, P.F.; J.J; A.E.; S.R.; M.M. and E.M.; statistical analysis, P.F and J.J; writing - original draft preparation, P.F.; J.J; A.E.; S.R.; M.M.; M.G.; E.M. and J.B.; writing - review and editing, P.F.; J.J; A.E.; S.R.; M.M.;E.M.; M.Y.; M.R.; M.T.; M.G.; L.C. and J.B. The supervisor of this project was J.J. All authors have read and agreed to the published version of the manuscript.

Funding: This work was supported by the Hestia Chair from Universitat Internacional de Catalunya (grant number BI-CHAISS-2019/003) and the research grant from the Catalan Board of Physiotherapists Code R03/19.

Institutional Review Board Statement: The study was conducted according to the guidelines of the Declaration of Helsinki, as well as the Organic Law 3/2018 (December 5) on the Protection of Personal Data and Guarantee of Digital Rights in Spain. The study received the following approvals: University of Vic - Central University of Catalonia (UVic-UCC) Ethics and Research Committee (92/2019) and Clinical Research Ethics Committee of the Osona Foundation for health research and education (FORES) (code 2020118/PR249).

Informed Consent Statement: Informed consent was obtained from all subjects involved in the study.

Data Availability Statement: The data presented in this study are available on request from the corresponding author.

Conflicts of Interest: The authors declare no conflict of interest and the funders had no role in the design of the study; in the collection, analyses, or interpretation of data; in the writing of the manuscript, or in the decision to publish the results. 


\section{References}

1. Ageing Europe - statistics on population developments - Statistics Explained [Internet]. [cited 2021 Dec 8]. Available from: https://ec.europa.eu/eurostat/statistics-explained/index.php?title=Ageing_Europe_-_statistics_on_population_developments\#Older_people_.E2.80.94_population_overview

2. Steiner UK, Larsen LA, Christensen K. Parallel progress in perceived age and life expectancy. Journals Gerontol - Ser A Biol Sci Med Sci. 2020;75(2):333-9.

3. Population structure and ageing - Statistics Explained [Internet]. [cited 2021 Dec 8]. Available from: https://ec.europa.eu/eurostat/statistics-explained/index.php?title=Population_structure_and_ageing

4. Abrams P, Blaivas JG, Stanton SL, Andersen JT. The standardisation of terminology of lower urinary tract function. The International Continence Society Committee on Standardisation of Terminology. Scand J Urol Nephrol Suppl [Internet]. 1988;114:5-19. Available from: http://www.ncbi.nlm.nih.gov/pubmed/3201169

5. Irwin DE, Milsom I, Hunskaar S, Reilly K, Kopp Z, Herschorn S, et al. Population-based survey of urinary incontinence, overactive bladder, and other lower urinary tract symptoms in five countries: results of the EPIC study. Eur Urol. 2006;50(6):1305-6.

6. Mourad S, Shokeir A, Ayoub N, Ibrahim M, Reynolds N, Donde S, et al. Prevalence and impact of lower urinary tract symptoms: Results of the epic survey in Egypt. Neurourol Urodyn. 2019;38(2):637-43.

7. Kogan MI, Zachoval R, Özyurt C, Schäfer T, Christensen N. Epidemiology and impact of urinary incontinence, overactive bladder, and other lower urinary tract symptoms: Results of the EPIC survey in Russia, Czech Republic, and Turkey. Curr Med Res Opin. 2014;30(10):2119-30.

8. Lee YS, Lee KS, Jung JH, Han DH, Oh SJ, Seo JT, et al. Prevalence of overactive bladder, urinary incontinence, and lower urinary tract symptoms: Results of Korean EPIC study. World J Urol. 2011;29(2):185-90.

9. Milsom I, Gyhagen M. The prevalence of urinary incontinence. Climacteric [Internet]. 2019;22(3):217-22. Available from: https://doi.org/10.1080/13697137.2018.1543263

10. Stickley A, Santini ZI, Koyanagi A. Urinary incontinence, mental health and loneliness among community-dwelling older adults in Ireland. BMC Urol. 2017;17(1):1-9.

11. Moon S, Chung HS, Kim YJ, Kim SJ, Kwon O, Lee YG, et al. The impact of urinary incontinence on falls: A systematic review and meta-analysis. PLoS One [Internet]. 2021;16(5 May):1-18. Available from: http://dx.doi.org/10.1371/journal.pone.0251711

12. Chiu A-F, Huang M-H, Hsu M-H, Liu J-L, Chiu J-F. Association of urinary incontinence with impaired functional status among older people living in a long-term care setting. Geriatr Gerontol Int [Internet]. 2015 Mar;15(3):296-301. Available from: http://www.ncbi.nlm.nih.gov/pubmed/25154884

13. Jachan DE, Müller-Werdan U, Lahmann NA. Impaired Mobility and Urinary Incontinence in Nursing Home Residents: A Multicenter Study. J Wound, Ostomy Cont Nurs. 2019;46(6):524-9.

14. Fedecostante M, Onder G, Eusebi P, Dell'Aquila G, Zengarini E, Carrieri B, et al. Predictors of Functional Decline in Nursing Home Residents: The Shelter Project. J Gerontol A Biol Sci Med Sci. 2020 Jul;75(8):1600-5.

15. Faleiro DJA, Menezes EC, Capeletto E, Fank F, Porto RM, Mazo GZ. Association of physical activity with urinary incontinence in older women: A systematic review. J Aging Phys Act. 2019;27(6):906-13.

16. Veronese N, Soysal P, Stubbs B, Marengoni A, Demurtas J, Maggi S, et al. Association between urinary incontinence and frailty: a systematic review and meta-analysis. Eur Geriatr Med. 2018;9(5):571-8.

17. Jerez-Roig J, Santos MM, Souza DLB, Amaral FLJS, Lima KC. Prevalence of urinary incontinence and associated factors in nursing home residents. Neurourol Urodyn. 2016;35(1):102-7.

18. Cheng S, Lin D, Hu T, Cao L, Liao H, Mou X, et al. Association of urinary incontinence and depression or anxiety: a metaanalysis. J Int Med Res. 2020;48(6).

19. Pizzol D, Demurtas J, Celotto S, Maggi S, Smith L, Angiolelli G, et al. Urinary incontinence and quality of life: a systematic review and meta-analysis. Aging Clin Exp Res [Internet]. 2021;33(1):25-35. Available from: https://doi.org/10.1007/s40520020-01712-y

20. Saga S, Vinsnes AG, Morkved S, Norton C, Seim A. What characteristics predispose to continence in nursing home residents?: A population-based cross-sectional study. Neurourol Urodyn. 2014;

21. Schumpf LF, Theill N, Scheiner DA, Fink D, Riese F, Betschart C. Urinary incontinence and its association with functional physical and cognitive health among female nursing home residents in Switzerland. BMC Geriatr [Internet]. 2017;17(1):18. Available from: http://dx.doi.org/10.1186/s12877-017-0414-7

22. DuBeau CE, Simon SE, Morris JN. The effect of urinary incontinence on quality of life in older nursing home residents. J Am Geriatr Soc. 2006;54(9):1325-33.

23. Khandelwal C, Kistler C. Diagnosis of urinary incontinence. Am Fam Physician. 2013 Apr;87(8):543-50.

24. Abrams P, Andersson KE, Birder L, Brubaker L, Cardozo L, Chapple C, et al. Fourth International Consultation on Incontinence Recommendations of the International Scientific Committee: Evaluation and treatment of urinary incontinence, pelvic organ prolapse, and fecal incontinence. Neurourol Urodyn. 2010;29(1):213-40.

25. Saga S, Vinsnes AG, Mørkved S, Norton C, Seim A. What characteristics predispose to continence in nursing home residents?: A population-based cross-sectional study. Neurourol Urodyn [Internet]. 2015 Apr 28;34(4):362-7. Available from: https://onlinelibrary.wiley.com/doi/10.1002/nau.22563 
26. Offermans MP, Du Moulin MF, Hamers JP, Dassen T, Halfens RJ. Prevalence of urinary incontinence and associated risk factors in nursing home residents: a systematic review. Neurourol Urodyn. 2009;28(4):288-94.

27. Rezende LFM, Sá TH, Mielke GI, Viscondi JYK, Rey-López JP, Garcia LMT. All-Cause Mortality Attributable to Sitting Time: Analysis of 54 Countries Worldwide. Am J Prev Med. 2016;51(2):253-63.

28. Fornias L, Rodrigues M, Rey-López J, Keihan V, Carmo O. Sedentary Behavior and Health Outcomes: An Overview of Systematic Reviews. PLoS One. 2014;9(8):105620.

29. Cheng W, Zhang Z, Cheng W, Yang C, Diao L, Liu W. Associations of leisure-time physical activity with cardiovascular mortality: A systematic review and meta-analysis of 44 prospective cohort studies. Eur J Prev Cardiol. 2018;25(17):1864-72.

30. Wullems JA, Verschueren SMP, Degens H, Morse CI, Onambélé GL. A review of the assessment and prevalence of sedentarism in older adults, its physiology/health impact and non-exercise mobility counter-measures. Vol. 17, Biogerontology. Springer Netherlands; 2016. p. 547-65.

31. Patterson R, McNamara E, Tainio M, de Sá TH, Smith AD, Sharp SJ, et al. Sedentary behaviour and risk of all-cause, cardiovascular and cancer mortality, and incident type 2 diabetes: a systematic review and dose response meta-analysis. Vol. 33, European Journal of Epidemiology. Springer Netherlands; 2018. p. 811-29.

32. Kehler DS, Hay JL, Stammers AN, Hamm NC, Kimber DE, Schultz ASH, et al. A systematic review of the association between sedentary behaviors with frailty. Vol. 114, Experimental Gerontology. Elsevier Inc.; 2018. p. 1-12.

33. Huang Y, Li L, Gan Y, Wang C, Jiang H, Cao S, et al. Sedentary behaviors and risk of depression: a meta-analysis of prospective studies. Transl Psychiatry [Internet]. 2020;10(1). Available from: http://dx.doi.org/10.1038/s41398-020-0715-z

34. Jerez-Roig J, Booth J, Skelton DA, Giné-Garriga M, Chastin SFM, Hagen S. Is urinary incontinence associated with sedentary behaviour in older women? Analysis of data from the National Health and Nutrition Examination Survey. PLoS One. 2020;15(2):e0227195.

35. Chu CM, Khanijow KD, Schmitz KH, Newman DK, Arya LA, Harvie HS. Physical Activity Patterns and Sedentary Behavior in Older Women With Urinary Incontinence. Female Pelvic Med Reconstr Surg [Internet]. 2018;24(4):1. Available from: http://insights.ovid.com/crossref?an=01436319-900000000-99639

36. Vinsnes AG, Helbostad JL, Nyrønning S, Harkless GE, Granbo R, Seim A. Effect of physical training on urinary incontinence: a randomized parallel group trial in nursing homes. Clin Interv Aging. 2012 Feb;7:45.

37. Stenzelius K, Molander U, Odeberg J, Hammarström M, Franzen K, Midlöv P, et al. The effect of conservative treatment of urinary incontinence among older and frail older people: A systematic review. Age Ageing. 2015;44(5):736-44.

38. Leirós-Rodríguez R, Romo-Pérez V, García-Soidán JL. Prevalencia de la incontinencia urinaria y su relación con el sedentarismo en España. Actas Urol Esp. 2017;41(10):624-30.

39. Rodolfo J, Araújo T De, Maria L, Macedo DB, Jerez-roig J, Lima KC De. Mobility Limitation in Older Adults Residing in Nursing Homes in Brazil Associated With Advanced Age and Poor Nutritional Status : An Observational Study. 2021;1-8.

40. Jerez-Roig J, Booth J, Skelton DA, Giné-Garriga M, Chastin SFM, Hagen S. Is urinary incontinence associated with sedentary behaviour in older women? Analysis of data from the National Health and Nutrition Examination Survey. Tan MP, editor. PLoS One [Internet]. 2020 Feb 4;15(2):e0227195. Available from: https://dx.plos.org/10.1371/journal.pone.0227195

41. Farrés-Godayol P, Jerez-Roig J, Minobes-Molina E, Yildirim M, Goutan-Roura E, Coll-Planas L, et al. Urinary incontinence and sedentary behaviour in nursing home residents in Osona, Catalonia: Protocol for the OsoNaH project, a multicentre observational study. BMJ Open. 2021;11(4):1-8.

42. von Elm E, Altman DG, Egger M, Pocock SJ, Gøtzsche PC, Vandenbroucke JP. The Strengthening the Reporting of Observational Studies in Epidemiology (STROBE) statement: guidelines for reporting observational studies. J Clin Epidemiol. 2008;61(4):344-9.

43. Klusch L. The MDS 3.0 and its impact on bladder and bowel care. Provider. 2012;38(6):33, 35, 37 passim.

44. Espuña Pons M, Rebollo Alvarez P, Puig Clota M. [Validation of the Spanish version of the International Consultation on Incontinence Questionnaire-Short Form. A questionnaire for assessing the urinary incontinence]. Med Clin (Barc) [Internet]. 2004 Mar;122(8):288-92. Available from: http://www.ncbi.nlm.nih.gov/pubmed/15030739

45. Badía X, García-Losa M, Dal-Ré R. Ten-language translation and harmonization of the International Prostate Symptom Score: developing a methodology for multinational clinical trials. Eur Urol. 1997;31(2):129-40.

46. Badia X, Garcia-Losa M, Dal-Re R, Carballido J, Serra M. Validation of a harmonized Spanish version of the IPSS: evidence of equivalence with the original American scale. International Prostate Symptom Score. Urology. 1998;52(4):614-20.

47. Edwardson CL, Winkler EAH, Bodicoat DH, Yates T, Davies MJ, Dunstan DW, et al. Considerations when using the activPAL monitor in field-based research with adult populations. Vol. 6, Journal of Sport and Health Science. Elsevier B.V.; 2017. p. 162-78.

48. Grant PM, Dall PM, Mitchell SL, Granat MH. Activity-monitor accuracy in measuring step number and cadence in community-dwelling older adults. J Aging Phys Act. 2008;16(2):201-14.

49. Kozey-Keadle S, Libertine A, Lyden K, Staudenmayer J, Freedson PS. Validation of Wearable Monitors for Assessing Sedentary Behavior. Med Sci Sport Exerc [Internet]. 2011 Aug;43(8):1561-7. Available from: https://journals.lww.com/00005768201108000-00023

50. Shah S, Vanclay F, Cooper B. Improving the sensitivity of the Barthel Index for stroke rehabilitation. J Clin Epidemiol. 1989;42(8):703-9.

51. Baztán JJ. Índice de Barthel : Instrumento válido para la valoración funcional de pacientes con enfermedad cerebrovascular. 2016;(March). 
52. Villanueva BP, Valdés CB, Gama EV, Bravo CV, Damián J. Prevalencia y principales características de la incontinencia urinaria en la población anciana institucionalizada de Madrid. Rev Esp Geriatr Gerontol. 2011;46(1):7-14.

53. Guralnik JM, Simonsick EM, Ferrucci L, Glynn RJ, Berkman LF, Blazer DG, et al. A Short Physical Performance Battery Assessing Lower Extremity Function: Association With Self-Reported Disability and Prediction of Mortality and Nursing Home Admission Energetic cost of walking in older adults View project IOM committee on cognitive agi. Artic J Gerontol. 1994;49(2):85-94.

54. Sipers WMWH, Verdijk LB, Sipers SJE, Schols JMGA, van Loon LJC. The Martin Vigorimeter Represents a Reliable and More Practical Tool Than the Jamar Dynamometer to Assess Handgrip Strength in the Geriatric Patient. J Am Med Dir Assoc. 2016;17(5):466.e1--466.e7.

55. Rockwood K. A global clinical measure of fitness and frailty in elderly people. Can Med Assoc J. 2005;173(5):489-95.

56. Collen FM, Wade DT, Robb GF, Bradshaw CM. The rivermead mobility index: A further development of the rivermead motor assessment. Disabil Rehabil. 1991;13(2):50-4.

57. Malmstrom TK, Morley JE. SARC-F: A simple questionnaire to rapidly diagnose sarcopenia. J Am Med Dir Assoc [Internet]. 2013;14(8):531-2. Available from: http://dx.doi.org/10.1016/j.jamda.2013.05.018

58. Malmstrom TK, Miller DK, Simonsick EM, Ferrucci L, Morley JE. SARC-F: A symptom score to predict persons with sarcopenia at risk for poor functional outcomes. J Cachexia Sarcopenia Muscle. 2016;7(1):28-36.

59. Janssen MF, Pickard AS, Golicki D, Gudex C, Niewada M, Scalone L, et al. Measurement properties of the EQ-5D-5L compared to the EQ-5D-3L across eight patient groups: A multi-country study. Qual Life Res. 2013;22(7):1717-27.

60. WHO Collaborating Centre for Drug Statistics Methodology. Guidelines for ATC classification and DDD assignment 2013. 16th ed. Oslo; 2012. 284 p.

61. Guigoz, Y.; Vellas, B. J.; Garry PJ. Mini Nutritional Assessment: a practical tool for grading the nutritional state of elderly patients. Facts Reserch Gerontol. 1994;4(2):15-59.

62. Martínez de la Iglesia J, Onís Vilches M, Dueñas Herrero R, Albert Colomer C, Aguado Taberné C, Luque Luque R. Versión española del cuestionario de Yesavage abreviado (GDS) para el despistaje de depresión en mayores de 65 años: adaptación y validación. Medifam. 2002;12(10):1206-12.

63. Martinez de la Iglesia J, Duenas Herrero R, Onis Vilches MC, Aguado Taberne C, Albert Colomer C, Luque Luque R. Spanish language adaptation and validation of the Pfeiffer's questionnaire (SPMSQ) to detect cognitive deterioration in people over 65 years of age. Med Clin (Barc). 2001;117(4):129-34.

64. Herrero MJ, Blanch J, Peri JM, De Pablo J, Pintor L, Bulbena A. A validation study of the hospital anxiety and depression scale (HADS) in a Spanish population. Gen Hosp Psychiatry. 2003;25(4):277-83.

65. Lubben J, Blozik E, Gillmann G, Iliffe S, Von Kruse WR, Beck JC, et al. Performance of an abbreviated version of the lubben social network scale among three European community-dwelling older adult populations. Gerontologist. 2006;46(4):50313.

66. Buz J, Adánez GP. Análisis de la escala de soledad de de jong gierveld mediante el modelo de rasch. Univ Psychol. 2013;12(3):971-81.

67. Roig JJ, Souza DLB de, Lima KC. Urinary incontinence in institutionalized elderly: prevalence and impact on quality of life. Fisioter em Mov [Internet]. 2015 Sep;28(3):583-96. Available from: http://www.scielo.br/scielo.php?script=sci_arttext\&pid=S0103-51502015000300583\&lng=en\&tlng=en

68. Musa MK, Saga S, Blekken LE, Harris R, Goodman C, Norton C. The Prevalence, Incidence, and Correlates of Fecal Incontinence Among Older People Residing in Care Homes: A Systematic Review. J Am Med Dir Assoc [Internet]. 2019;20(8):956962.e8. Available from: https://doi.org/10.1016/j.jamda.2019.03.033

69. Bosch JL, Weiss JP. The prevalence and causes of nocturia. J Urol. 2013;189(1 Suppl):S86----92.

70. Booth J, McMillan L. The impact of nocturia on older people - implications for nursing practice. Br J Nurs. 2009;18(10):5926.

71. Mendes A, Hoga L, Gonçalves B, Silva P, Pereira P. Adult women's experiences of urinary incontinence: A systematic review of qualitative evidence. JBI Database Syst Rev Implement Reports. 2017;15(5):1350-408.

72. Elenskaia K, Haidvogel K, Heidinger C, Doerfler D, Umek W, Hanzal E. The greatest taboo: Urinary incontinence as a source of shame and embarrassment. Wien Klin Wochenschr. 2011;123(19-20):607-10.

73. Toye F, Barker KL. A meta-ethnography to understand the experience of living with urinary incontinence: "Is it just part and parcel of life?" BMC Urol. 2020;20(1).

74. Vethanayagam N, Orrell A, Dahlberg L, McKee KJ, Orme S, Parker SG, et al. Understanding help-seeking in older people with urinary incontinence: an interview study. Heal Soc Care Community. 2017;25(3):1061-9.

75. Ehlman K, Wilson A, Dugger R, Eggleston B, Coudret N, Mathis S. Nursing home staff members' attitudes and knowledge about urinary incontinence: the impact of technology and training. Urol Nurs. 2012;32(4):205-13.

76. Xu D, Kane RL. Effect of urinary incontinence on older nursing home residents' self-reported quality of life. J Am Geriatr Soc. $2013 ; 61(9): 1473-81$.

77. Dubeau CE, Simon SE, Morris JN. The effect of urinary incontinence on quality of life in older nursing home residents. J Am Geriatr Soc. 2006;54(9):1325-33.

78. Jerez-Roig J, Souza DLB de, Lima KC. Incontinência urinária em idosos institucionalizados no Brasil: uma revisão integrativa. Rev Bras Geriatr e Gerontol. 2013;16(4):865-79. 
79. Engström G, Henningsohn L, Steineck G, Leppert J. Self-assessed health, sadness and happiness in relation to the total burden of symptoms from the lower urinary tract. BJU Int. 2005;95(6):810-5.

80. Ojewola RW, Oridota ES, Balogun OS, Ogundare EO, Alabi TO. Lower Urinary Tract Symptoms: Prevalence, Perceptions, and Healthcare-Seeking Behavior amongst Nigerian Men. World J Mens Health. 2016;34(3):200.

81. Adegun PT, Adebayo PB, Areo PO. Severity of lower urinary tract symptoms among middle aged and elderly Nigerian men: Impact on quality of life. Adv Urol. 2016;2016.

82. Dunstan DW, Kingwell BA, Larsen R, Healy GN, Cerin E, Hamilton MT, et al. Breaking up prolonged sitting reduces postprandial glucose and insulin responses. Diabetes Care. 2012;35(5):976-83.

83. Chu CM, Khanijow KD, Schmitz KH, Newman DK, Arya LA, Harvie HS. Physical Activity Patterns and Sedentary Behavior in Older Women With Urinary Incontinence: an Accelerometer-based Study. Female Pelvic Med Reconstr Surg [Internet]. 2019 Jul;25(4):318-22. Available from: https://journals.lww.com/01436319-201907000-00012

84. Marmeleira J, Ferreira S, Raimundo A. Physical activity and physical fitness of nursing home residents with cognitive impairment: A pilot study. Exp Gerontol. 2017;100:63-9.

85. Aly WW, Sweed HS, Mossad NA, Tolba MF. Prevalence and Risk Factors of Urinary Incontinence in Frail Elderly Females. J Aging Res. 2020;2020.

86. Coll-Planas L, Denkinger MD, Nikolaus T. Relationship of urinary incontinence and late-life disability: Implications for clinical work and research in geriatrics. 2008;290:283-90.

87. Bag Soytas R, Soytas M, Danacioglu YO, Citgez S, Yavuzer H, Can G, et al. Relationship between the types of urinary incontinence, handgrip strength, and pelvic floor muscle strength in adult women. Neurourol Urodyn. 2021;40(6):1532-8.

88. Casey EK, Temme K. Pelvic floor muscle function and urinary incontinence in the female athlete. Phys Sportsmed [Internet]. 2017;45(4):399-407. Available from: https://doi.org/10.1080/00913847.2017.1372677 